\title{
Addressing Concerns toward Xenotransplantation
}

\author{
Daniel Hurst ${ }^{1}$, Lluz Padilla ${ }^{2}$, Wayne Paris ${ }^{3}$, David Cooper ${ }^{2}$, and David Cleveland ${ }^{2}$ \\ ${ }^{1}$ Rowan University School of Osteopathic Medicine \\ ${ }^{2}$ The University of Alabama at Birmingham \\ ${ }^{3}$ Abilene Christian University
}

September 24, 2021

\begin{abstract}
There is increasing attention being given toward social and ethical implications of xenotransplantation that may begin relatively soon. IN a recent commentary by Loebe and Parker, the authors address many of the social and ethical issues in regard to xenotransplantation, but do so only superficially. This letter to the editor responds to many of the points they raise.
\end{abstract}

\section{Addressing Concerns toward Xenotransplantation}

1. Daniel J. Hurst, PhD, ThM, MSc (corresponding author)

Director of Medical Professionalism, Ethics, and Humanities

Assistant Professor, Department of Family Medicine

Rowan University School of Osteopathic Medicine

42 E. Laurel Road

Stratford, NJ 08084

hurst@rowan.edu

office: 856-566-6246

2. Luz Padilla, MD, MSPH

Assistant Professor, Departments of Surgery and Epidemiology

The University of Alabama at Birmingham

lpadilla@uabmc.edu

3. Wayne Paris, PhD, MSW

Professor Emeritus

School of Social Work

Abilene Christian University

wdp10a@acu.edu

4. David KC Cooper, MD, PhD, FRCS

Co-Director, Xenotransplantation Program Department of Surgery 
The University of Alabama at Birmingham

dkcooper@uabmc.edu

5. David C. Cleveland, MD, MBA

Department of Surgery

The University of Alabama at Birmingham

dcleveland@uabmc.edu

\section{Addressing Concerns toward Xenotransplantation}

To the editor:

Social and ethical implications of xenotransplantation are receiving increasing attention as clinical trials are projected to take place soon. Unfortunately, the recent commentary by Loebe and Parker11Loebe M, Parker B. Don't pig(!) the wrong heart! [published online ahead of print, 2021 Jul 26]. J Card Surg . 2021;10.1111/jocs.15842. addresses the ethical issues superficially. We agree that great need exists to find long-term relief to end-stage organ dysfunction, but our viewpoints differ in some key areas.

The arguments for mechanical circulatory devices they make are not applicable to infants with life-threatening congenital heart disease, in whom the outcomes of device support are disappointing. ${ }^{1}$ There is also disregard for the scientific evidence that indicates that, because of their immature immune system, infants pose a unique biological opportunity over adults with heart failure. ${ }^{2}$

The authors reference several of our studies that raise the very concerns they note but disregard the conclusions reached. Our interdisciplinary group has conducted multiple research surveys and focus groups to elicit the public's perception of pediatric cardiac and adult kidney xenotransplantation. ${ }^{3-5}$ We have consulted numerous stakeholders, including religious leaders, organ procurement staff/administrators, healthcare providers who care for possible future candidates, patients themselves, parents of children who may need an organ or are transplant recipients, and local businesspersons. ${ }^{3-5}$ In summary, these studies found little or no religious, ethical, or social concerns among these stakeholders, with considerable support for xenotransplantation given results are comparable to allotransplantation (which, of course, is not yet known). There was also support for its use to bridge patients until a deceased human donor organ could be obtained, which is our suggested therapy for infants. This would not commit the child to a lifetime of support by a pig heart.

Although, as the authors state, the results of pig heart transplantation in nonhuman primates do not yet support a clinical trial, progress is certainly being made. The fact that it has taken decades to explore this alternative can be evidence of the tactful and serious standards the scientific community is taking before its consideration. We agree more work remains especially in the pediatric field and suggest openness to the potential of xenotransplantation remains warranted.

\section{References:}

1. Cleveland D, Adam Banks C, Hara H, Carlo WF, Mauchley DC, Cooper DKC. The case for cardiac xenotransplantation in neonates: Is now the time to reconsider xenotransplantation for hypoplastic left heart syndrome?. Pediatr Cardiol . 2019;40(2):437-444.

2. Padilla LA, Rhodes L, Sorabella RA, et al. Attitudes toward xenotransplantation: A survey of parents and pediatric cardiac providers. Pediatr Transplant. 2020:e13851.

3. Hurst DJ, Padilla LA, Cooper DKC, Paris W. Factors influencing attitudes toward xenotransplantation clinical trials: a report of focus group studies. Xenotransplantation. 2021:e12684.

4. Padilla LA, Hurst D, Lopez R, Kumar V, Cooper DKC, Paris W. Attitudes to clinical pig kidney xenotransplantation among medical providers and patients. Kidney360. 2020;1(7):657-662. 
5. Padilla L, Sorabella R, Carlo W, et al. Attitudes to cardiac xenotransplantation by pediatric heart surgeons and physicians. World J Pediatr Congenit Heart Surg. 2020;11(4):426-430. 